\title{
False lumen pressure estimation in type $B$ aortic dissection using 4D flow cardiovascular magnetic resonance: comparisons with aortic growth
}

David Marlevi ${ }^{1 \dagger}$, Julio A. Sotelo ${ }^{2,3,4 \dagger}$, Ross Grogan-Kaylor ${ }^{6}$, Yunus Ahmed ${ }^{7}$, Sergio Uribe ${ }^{3,4,5}$, Himanshu J. Patel ${ }^{7}$, Elazer R. Edelman', David A. Nordsletten ${ }^{6,7,8}$ and Nicholas S. Burris ${ }^{6, *^{*}}$

\begin{abstract}
Background: Chronic type B aortic dissection (TBAD) is associated with poor long-term outcome, and accurate risk stratification tools remain lacking. Pressurization of the false lumen ( $F L)$ has been recognized as central in promoting aortic growth. Several surrogate imaging-based metrics have been proposed to assess FL hemodynamics; however, their relationship to enlarging aortic dimensions remains unclear. We investigated the association between aortic growth and three cardiovascular magnetic resonance (CMR)-derived metrics of FL pressurization: false lumen ejection fraction (FLEF), maximum systolic deceleration rate (MSDR), and FL relative pressure ( $\left.F L \triangle \mathrm{P}_{\text {max }}\right)$.

Methods: CMR/CMR angiography was performed in 12 patients with chronic dissection of the descending thoracoabdominal aorta, including contrast-enhanced CMR angiography and time-resolved three-dimensional phase-contrast CMR (4D Flow CMR). Aortic growth rate was calculated as the change in maximal aortic diameter between baseline and follow-up imaging studies over the time interval, with patients categorized as having either 'stable' $(<3 \mathrm{~mm} /$ year) or 'enlarging' ( $\geq 3 \mathrm{~mm} /$ year) growth. Three metrics relating to FL pressurization were defined as: (1) FLEF: the ratio between retrograde and antegrade flow at the TBAD entry tear, (2) MSDR: the absolute difference between maximum and minimum systolic acceleration in the proximal $F L$, and (3) $F L \triangle P_{\text {max }}$ : the difference in absolute pressure between aortic root and distal FL.
\end{abstract}

Results: FLEF was higher in enlarging TBAD (49.0 $\pm 17.9 \%$ vs. $10.0 \pm 11.9 \%, p=0.002)$, whereas FL $\triangle P_{\text {max }}$ was lower ( $32.2 \pm 10.8$ vs. $57.2 \pm 12.5 \mathrm{mmHg} / \mathrm{m}, \mathrm{p}=0.017$ ). MSDR and conventional anatomic variables did not differ significantly between groups. FLEF showed positive $(r=0.78, p=0.003)$ correlation with aortic growth rate whereas $F L \Delta P_{\max }$ showed negative correlation ( $r=-0.64, p=0.026$ ). FLEF and $F L \Delta P_{\max }$ remained as independent predictors of aortic growth rate after adjusting for baseline aortic diameter.

Conclusion: Comparative analysis of three 4D flow CMR metrics of TBAD FL pressurization demonstrated that those that focusing on retrograde flow (FLEF) and relative pressure ( $F L \triangle P_{\text {max }}$ ) independently correlated with growth and differentiated patients with enlarging and stable descending aortic dissections. These results emphasize the highly

\footnotetext{
*Correspondence: nburris@med.umich.edu

${ }^{\dagger}$ David Marlevi and Julio A. Sotelo contributed equally to this work and share the first authorship position

${ }^{6}$ Department of Biomedical Engineering, University of Michigan, Ann Arbor, MI, USA

Full list of author information is available at the end of the article
}

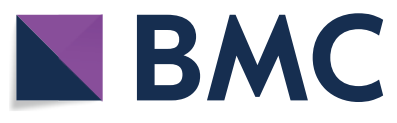

The Author(s) 2021. Open Access This article is licensed under a Creative Commons Attribution 4.0 International License, which permits use, sharing, adaptation, distribution and reproduction in any medium or format, as long as you give appropriate credit to the original author(s) and the source, provide a link to the Creative Commons licence, and indicate if changes were made. The images or other third party material in this article are included in the article's Creative Commons licence, unless indicated otherwise in a credit line to the material. If material is not included in the article's Creative Commons licence and your intended use is not permitted by statutory regulation or exceeds the permitted use, you will need to obtain permission directly from the copyright holder. To view a copy of this licence, visit http://creativecommons.org/licenses/by/4.0/. The Creative Commons Public Domain Dedication waiver (http://creativeco mmons.org/publicdomain/zero/1.0/) applies to the data made available in this article, unless otherwise stated in a credit line to the data. 
variable nature of aortic hemodynamics in TBAD patients, and suggest that 4D Flow CMR derived metrics of FL pressurization may be useful to separate patients at highest and lowest risk for progressive aortic growth and complications.

Keywords: Type B aortic dissection, 4D flow magnetic resonance imaging, 4D flow MRI, False lumen, Aortic growth rate, False lumen ejection fraction, Maximum systolic deceleration rate, Relative pressure

\section{Introduction}

Chronic type B aortic dissection (TBAD) is characterized by high incidence of long-term complications and elevated mortality [1], with progressive growth of the false lumen (FL) being a primary contributor to adverse outcomes [2]. Thoracic endovascular aortic repair (TEVAR) has been increasingly used to reduce aneurysm formation in TBAD [3, 4], however, TEVAR does not yield favorable results in all patients, particularly those with chronic dissection, and comes with procedural risks [5, 6]. Thus, there is a significant need for better techniques to assess risk of FL growth to identify patients who may benefit most from prophylactic repair.

Current methods for predicting growth in TBAD are based on anatomic features, most commonly maximal aortic diameter [7]. However, such evaluation does not include assessment of abnormal blood flow [7-9], which is believed to play an important role in driving aortic growth. An increasing body of experimental evidence [10-17] has demonstrated that an excess of FL inflow relative to outflow leads to increasing pressurization of the FL, which promotes growth due to elevated stresses on the weakened aortic wall. Despite the importance of FL pressurization, current techniques to measure FL pressures require invasive catheterization, which is potentially hazardous and rarely performed clinically. Thus, there remains a significant need for clinically applicable techniques to quantify FL pressure and hemodynamic abnormalities in vivo to advance translation of these experimental findings to clinical care of TBAD patients.

Time-resolved three-dimensional phase-contrast cardiovacular magnetic resonance (4D Flow CMR) is a noninvasive technique that provides volumetric assessment of blood flow, and has been extensively applied to study aortic hemodynamics [18-23]. Recent 4D Flow CMR studies have also proposed ways of estimating FL pressurization and to predict growth in TBAD [18-20, 24]. Burris et al. [18] proposed FL ejection fraction (FLEF)-the ratio between retrograde and antegrade flow through the FL opening-as indicative of pressurization, linking FLEF to TBAD growth. Similarly, Ruiz Munoz et al. [24] used 4D flow CMR to measure the maximum systolic deceleration rate (MSDR) in the FL as a marker of FL pressurization and found significant associations between MSDR and aortic growth rate.
Despite the intuitive nature of FLEF and MSDR, these parameters are indirect methods for estimating FL pressure. However, recent technical advancements in physics-based image analysis have allowed for non-invasive measurement of intravascular pressure drop from 4D Flow data. $v$ WERP (virtual Work-Energy Relative Pressure) is such a technique, which uses a virtual workenergy formulation of the Navier-Stokes equations to provide accurate estimates of relative pressure through complex vascular anatomies [25]. $v$ WERP has even been shown to provide accurate measurements (errors of $<1 \mathrm{mmHg}$ ) of relative pressure in the $\mathrm{TL}$ and $\mathrm{FL}$ insilico, and has been validated against invasive catheterization in-vivo [25]. $v$ WERP is thus a promising utility for quantifying intravascular pressure changes in TBAD.

The objective of this study was twofold. First, we aimed to establish the correlation between three techniques for non-invasive estimation of FL pressurization (FLEF, MSDR, and relative pressure changes derived by $v$ WERP), and their relation to anatomic risk factors in TBAD. Secondly, we sought to better understand each method's potential applicability for patient risk-stratification by examining associations between aortic growth rate and metrics of FL pressurization in TBAD patients.

\section{Methods}

Patient identification and clinical/anatomic characteristics Between November 2014 and August 2019, 22 adult patients with medically managed descending thoracic aorta dissection $(\mathrm{n}=19$ type $\mathrm{B} ; \mathrm{n}=3$ repaired type $\mathrm{A})$ were prospectively enrolled in an IRB-approved study (HUM00120679) and underwent a single research CMR. Patients who underwent research CMR were excluded from analysis for the following reasons: complete FL thrombosis $(\mathrm{n}=1)$, entry tear in the abdominal aorta $(\mathrm{n}=1)$, arrhythmia-related artifact $(\mathrm{n}=3)$, non-contrast CMR $(n=3)$ or incomplete CMR examination due to claustrophobia $(n=2)$, resulting in 12 patients available for complete analysis $(n=11$ type $B ; n=1$ repaired type A). All patients had involvement of the descending thoracoabdominal aorta with dominant (i.e., largest) entry tears in the thoracic segment. Clinical and demographic information was collected by research questionnaire and chart review. Baseline anatomic data was measured on the clinical computed tomography $(\mathrm{CT})$ scan acquired at 
the time of dissection using standard 3D software (Vitrea version 6.9, Vital Images, Toshiba, Tokyo, Japan).

\section{CMR imaging technique and image analysis}

Acquisition: All CMR exams were performed on 3 T scanners ( $\mathrm{n}=1$ : MR750, General Electric Healthcare, Milwaukee, Wisconsin, USA; $n=11$ : Ingenia, Philips Healthcare, Best, The Netherlands). The CMR examination included breath-hold, contrast-enhanced magnetic resonance angiography (CE-MRA), using retrospective gating with arrhythmia rejection, and reconstructed at $0.9 \mathrm{~mm}$ isotropic resolution after the administration of an ironbased contrast agent (ferumoxytol, $3 \mathrm{mg} / \mathrm{kg}$ ) in 7 patients at $3 \mathrm{mg} / \mathrm{kg}$ dose or gadobenate dimeglumine (Multihance ${ }^{\circledR}$; Bracco, Milano, Italy) in 5 patients at $0.2 \mathrm{~mL} / \mathrm{kg}$ dose. Following the CE-MRA, 4D Flow CMR was performed covering the thoracic aorta. Briefly, 4D Flow scan parameters included: flip angle $=15$ degrees, reconstructed resolution = approximately $1.5 \times 1.5 \times 2.5 \mathrm{~mm}$, acceleration factor $=2.0 \times 2.0$, views-per-segment $=3$, average scan time $=11 \mathrm{~min}$, and average temporal resolution $=47 \mathrm{~ms}$, velocity encoding value $=200 \mathrm{~cm} / \mathrm{sec}$. Patient blood pressure was measured by brachial cuff, immediately before commencing scanning, while laying on the scanner table outside of the bore.

CMR post-processing: The true lumen (TL) and FL segmentations were generated with dedicated software (Mimics, Materialise, Leuven, Belgium) on CE-MRA images, using contrast thresholding and manual refinement. Once the segmentations were completed, an inhouse MATLAB (MathWorks, Natick, Massachusetts, USA) toolbox [26, 27] was utilized to perform a range of image processing steps: (a) CE-MRA images and 4D Flow CMR were co-aligned using the transformation matrices obtained by the DICOMs tags of both images. (b) CEMRA images and corresponding segmentations were resampled into the 4D Flow CMR coordinate frame, using linear interpolation. (c) Rigid registration was performed to refine alignment of the TL and FL segmentations with the 4D Flow CMR data. Registration quality was visually assessed by confirming overlap between TL segmentations and the TL time-averaged phase contrast MRA (PC-MRA). In cases where registrations were flagged as in need of further improvement, segmentations were manually adjusted. (d) Lastly, TL and FL segmentations were refined to remove erroneous static tissue voxels at the luminal wall. Once complete, all images were saved for subsequent hemodynamic assessment. A simplified summary of the post-processing of the input data is shown in Fig. 1a.

False lumen ejection fraction: 4D Flow CMR DICOM data was uploaded to a web-based software application (Arterys, San Francisco, California, USA) for data reconstruction, visualization and flow analysis. Using this software, FLEF was calculated from the 4D Flow CMR data by performing flow analysis in the plane of the dominant entry tear and using a region of interest that limits measurements to flow through the tear. FLEF was defined as the ratio of retrograde flow volume at the tear during diastole over the antegrade flow volume. The FLEF quantification process is shown in Fig. 1b [18].

Maximum systolic flow deceleration rate: To calculate MSDR, a subsection of the FL positioned between the proximal tear and the pulmonary bifurcation, was extracted from the 4D Flow CMR data as described by Ruiz Munoz et al. [24]. In cases where the tear was located at the mid descending aorta, a subsection of $5 \mathrm{~cm}$ in length was created around the entry tear. From each subsection, acceleration data was extracted by calculating the time derivative of the mean velocity magnitude in the selected subsection. Using an averaged acceleration trace, MSDR was calculated as the difference between maximum and minimum acceleration during systole, divided by the corresponding time interval between these two points, generating a measure of acceleration or deceleration rate. The MSDR quantification process is shown in Fig. 1c.

$\nu W E R P$ relative pressure analysis: $\nu \mathrm{WERP}$ was used to assess the development of intraaortic pressure through the TL and FL [25]. The registered segmentations of TL and FL were used as input, with both segmentations connected to the proximal undissected ascending aorta. Relative aortic pressure changes were computed for the $\mathrm{TL}$ and FL over a segment from the ascending aorta to the distal FL at the level of the diaphragm (see Additional file 1: Appendix A and Marlevi et al. [25] for technical method details). To account for potential differences in intersubject anatomy, relative pressure traces were normalized by aortic length. From each relative pressure trace, maximum $\left(\Delta \mathrm{P}_{\max }\right)$ and minimum relative pressure $\left(\Delta \mathrm{P}_{\text {min }}\right)$ was derived for the TL and FL. Additionally, the transseptal pressure difference was computed by subtracting TL and FL relative pressure. These relative pressures (i.e., TL, FL and transseptal) were chosen for analysis, with positive and negative relative pressures quantifying the acceleration and deceleration of flow through TL and FL, and transseptal pressure representing the force exerted on the dissection septum/flap. The $v$ WERP quantification process is shown in Fig. 1d.

Outcome: The outcome variable in this study was aortic growth rate, calculated as the change in maximal aortic diameter between baseline computed tomography (CT) angiography and the CE-MRA, measured at the location of maximal aortic diameter of the dissected descending thoracoabdominal aorta, divided by the time interval between scans. Maximal diameter measurements were 


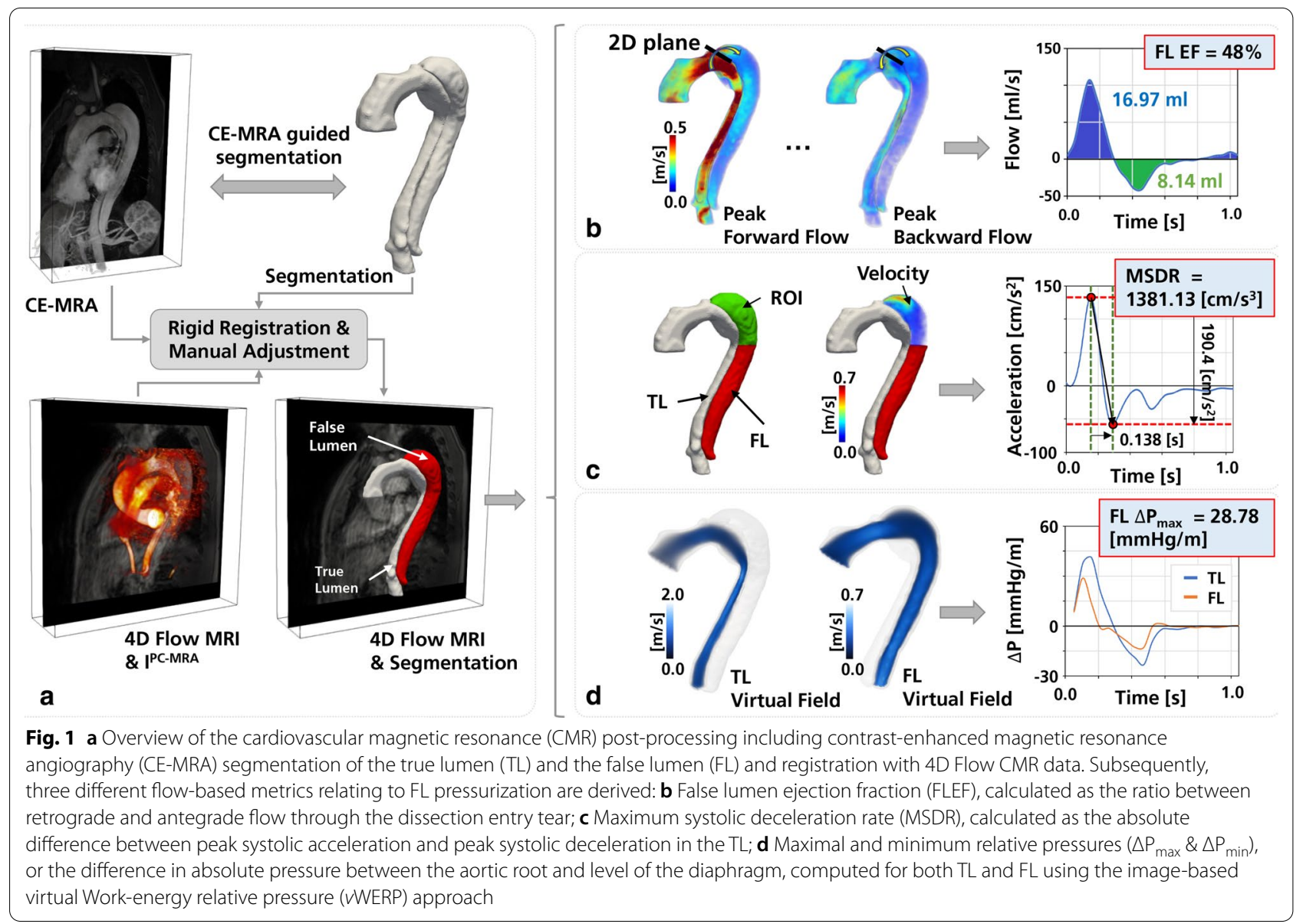

performed by a reviewer with over 10 years of experience with aortic imaging (N.B.), in a side-by-side fashion using double-oblique and inner-wall to inner-wall measurement technique as this approach has been shown to yield excellent inter-modality measurement agreement [28]. Subjects were categorized as "stable" if their aortic growth rate was $<3 \mathrm{~mm} /$ year and "enlarging" if the rate was $\geq 3 \mathrm{~mm} /$ year [29].

Reproducibility analysis: To assess the reproducibility of the FLEF measurements, a second independent rater with 4 years experience with aortic imaging, who was blinded to aortic growth data, performed manual definition of the entry tear plane and subsequent FLEF measurements on the TBAD 4D Flow datasets. Subsequently, once FLEF re-measurements were finalized, the same reviewer performed re-measurement of maximal aortic dimensions at baseline and follow-up CTs with subsequent determination of aortic growth.

For MSDR and FL $\Delta \mathrm{P}_{\max }$, the CE-MRA and 4D Flow CMR datasets were re-aligned using the same procedure described in CMR post-processing above, and subsequently, three sets of alterations were introduced to represent different modes of segmentation variations: one being systematically smaller than the original segmentations (representing the instance of threshold segmentation using a more conservative threshold value), one being systematically larger than the original segmentations (representing the instance of threshold segmentation using a more inclusive threshold value), and one being interchangeable smaller or larger with alterations varying along the length of the aorta (representing the instance of manual segmentation). For all sets, MSDR and FL $\Delta \mathrm{P}_{\max }$ were re-evaluated (for details on the reproducibility analysis, see Additional file 1: Appendix B).

Measurement reproducibility was assessed using Pearson's correlations, limits-of-agreement (LOA) statistics and Bland-Altman plots.

\section{Statistics}

Patient characteristics are reported as mean \pm SD for normally distributed continuous variables, medial and interquartile range (IQR) for non-normal continuous variables, and frequencies for categorical variables. Normality was assessed using the Shapiro-Wilk test. 
Pearson's correlation was used to determine associations between aortic growth rate, anatomic and hemodynamic parameters. Comparison of group means for continuous variables was performed with unpaired t-tests or MannWhitney $U$ test. Chi-square analysis and Fisher's exact test were used to evaluate differences in frequency of categorical variables. Pairwise correlation matrices were used to identify multicollinearity amongst predictors. Subsequently, multiple linear regression models with robust standard errors were used to examine the association of hemodynamic metrics with aortic growth after adjusting for baseline aortic diameter. A $p$-value of $<0.05$ was considered significant for all statistical tests. Statistical analyses were performed using Stata (version 14.0, StataCorp LP, College Station, Texas, USA).

\section{Results}

\section{Patient characteristics}

Patient and anatomic characteristics are reported in detail Table 1 . The average patient age was $54.9 \pm 9.6$ years (range: $31-71$ years), with a majority of the patients being male (75\%). A majority of the patients had a history of hypertension (83\%), whereas only a minority had an established history of connective tissue disease (25\%), and frequencies of these variables did not significantly differ between stable and enlarging groups. Mean systolic and diastolic blood pressure were $130 \pm 18$ (range: $98-152 \mathrm{mmHg}$ ) and $70 \pm 13 \mathrm{mmHg}$ (range: $49-89 \mathrm{mmHg}$ ), respectively, and the mean heart rate was $57 \pm 8 \mathrm{bpm}$ (range: $47-75 \mathrm{bpm}$ ). All patients were receiving beta-blockers for medical management, and at the time of CMR the majority of patients (8/12) were considered to be achieving a blood pressure goal of $<140 / 90 \mathrm{mmHg}$; among the 4 patients who were not at blood pressure goal, 3 were in the enlarging group and 1 was in the stable group. The average age of the dissection at the time of CMR was $3.6 \pm 3.3$ years. Patients in the stable group had a significantly longer history of dissection $(7.8 \pm 0.3$ vs. $1.5 \pm 1.5$ years for the enlarging group, $\mathrm{p}<0.001)$.

Regarding anatomical variables, the maximum baseline aortic diameter (based on index CT) was $41.3 \pm 8.4 \mathrm{~mm}$ (range: $29-58 \mathrm{~mm}$ ), increasing to $48.8 \pm 8.9 \mathrm{~mm}$ (range: 32-62 $\mathrm{mm}$ ) at the time of CMR, and the median aortic growth rate between baseline CT and CMR was $6.1 \mathrm{~mm} /$ year (IQR: $1.3-11.0$; range: $0-21.7 \mathrm{~mm} /$ year). The mean entry tear size was $17.8 \mathrm{~mm}$ (IQR: $14.5-21.3 \mathrm{~mm}$ ), and the distance of the entry tear from the left subclavian artery was $20.0 \mathrm{~mm}$ (IQR: 7.5-31.0 mm). As would be expected, aortic growth rate was significantly higher in the enlarging subgroup $(11.1 \pm 7.0 \mathrm{~mm} /$ year vs. $0.6 \pm 0.9 \mathrm{~mm} /$ year, $\mathrm{p}=0.004)$. Anatomical variables including dissection length, entry tear size, distance of the entry tear from the left subclavian artery and baseline maximal diameter were similar between groups $(\mathrm{p}=\mathrm{NS})$. Note that for the anatomical magnitude images, difference in signal-to-noise (SNR) was inferred between the two utilized contrast agents $(21.5 \pm 5.7$ vs. $55.9 \pm 18.5$,

Table 1 Patient characteristics and demographics

\begin{tabular}{|c|c|c|c|c|}
\hline Characteristics & Overall $(n=12)$ & Stable $(n=4)$ & Enlarging $(n=8)$ & p-value \\
\hline Patient age (years) & $\begin{array}{l}54.9 \pm 9.6 \\
\text { (range: } 31-71 \text { ) }\end{array}$ & $47.8 \pm 11.5$ & $58.5 \pm 6.6$ & 0.157 \\
\hline Sex (male/female), n & $9 / 3$ & $3 / 1$ & $6 / 2$ & 1.000 \\
\hline Hypertension, n (\%) & $10(83)$ & $2(50)$ & $8(100)$ & 0.091 \\
\hline Smoking history, n (\%) & $6(50)$ & $1(25)$ & $5(63)$ & 0.545 \\
\hline History of connective tissue disease, n (\%) & $3(25)$ & $2(50)$ & $1(12)$ & 0.236 \\
\hline Age of dissection at CMR (years) & $3.6 \pm 3.3$ (range: $0.2-8.0$ ) & $7.8 \pm 0.3$ & $1.5 \pm 1.5$ & $<0.001$ \\
\hline Maximum diameter at baseline ( $\mathrm{mm})$ & $41.3 \pm 8.4$ (range: $29-58)$ & $38.0 \pm 6.1$ & $42.9 \pm 9.2$ & 0.302 \\
\hline Maximum diameter at CMR (mm) & $48.8 \pm 8.9$ (range: $32-62)$ & $42.3 \pm 10.4$ & $51.8 \pm 6.8$ & 0.187 \\
\hline Aortic growth rate $(\mathrm{mm} / \mathrm{year})^{*}$ & $6.1(1.3-11.0)$ (range: $0-21.7)$ & $0.6(0-2.0)$ & $11.1(3.3-21.7)$ & 0.004 \\
\hline Thoracic aortic dissection length (cm) & $25.9 \pm 3.6$ (range: $18.4-32.4)$ & $27.4 \pm 4.1$ & $25.1 \pm 3.3$ & 0.364 \\
\hline Entry tear distance from left subclavian artery $(\mathrm{mm})^{*}$ & $\begin{array}{l}20.0(7.5-31) \\
\text { (range: } 0-130)\end{array}$ & $20.0(7.5-76)$ & $20.0(9.5-31)$ & 0.932 \\
\hline Dominant entry tear size by $\mathrm{CMR}(\mathrm{mm})^{*}$ & $\begin{array}{l}17.8(14.5-21.3) \\
\text { (range: } 10.8-44.5)\end{array}$ & $24.3(14.2-37.8)$ & $17.6(14.5-20.3)$ & 0.500 \\
\hline Systolic blood pressure (mmHg) & $130 \pm 18$ (range: $98-152)$ & $122 \pm 16$ & $134 \pm 19$ & 0.307 \\
\hline Diastolic blood pressure (mmHg) & $70 \pm 13$ (range: 49-89) & $70 \pm 12$ & $70 \pm 14$ & 1.000 \\
\hline Pulse pressure by CMR (mmHg) & $60 \pm 11$ (range: $44-80)$ & $52 \pm 8$ & $64 \pm 11$ & 0.070 \\
\hline Heart rate (bpm) & $57 \pm 8$ (range: $47-75)$ & $57 \pm 9$ & $57 \pm 8$ & 0.931 \\
\hline
\end{tabular}

${ }^{*}$ Median (IQR) 
$\mathrm{p}=0.003$, for ferumoxytol vs. multihance), with SNR calculated as the mean velocity in the entire segmented aorta divided by the standard deviation of the background noise, identified in a region outside the thoracic cavity [30].

\section{Hemodynamic assessment}

Mean cardiac output was $4.9 \pm 0.9 \mathrm{l} / \mathrm{min}$, mean ascending aortic forward flow was $87.4 \pm 21.7 \mathrm{ml} /$ beat and mean ascending aortic reverse flow was $-7.7 \pm 7.5 \mathrm{ml} /$ beat; these parameters did not differ between stable and enlarging groups.

The average net flow rate was higher in the TL than in the FL $(3.4 \pm 1.1$ vs. $1.5 \pm 1.4 \mathrm{l} / \mathrm{min}, \mathrm{p}=0.004)$. Peak velocity of the entry tear jet was similar between stable and enlarging groups $(108.1 \pm 11.7$ vs. $99.2 \pm 8.7 \mathrm{~cm} / \mathrm{s}$, $\mathrm{p}=0.56$ ). Overall mean FLEF was $36.0 \pm 24.7 \%$ (range 0 to $88 \%$ ) and FLEF was significantly higher in enlarging vs stable aortic dimensions $(49.0 \pm 17.9 \%$ vs $10.0 \pm 11.9 \%$, $\mathrm{p}=0.002$ ). In comparison, overall mean MSDR was $1401 \pm 956 \mathrm{~cm} / \mathrm{s}^{3}$ and did not differ significantly between groups $\left(1146 \pm 782\right.$ vs. $\left.1529 \pm 1058 \mathrm{~cm} / \mathrm{s}^{3}, \mathrm{p}=0.499\right)$. For the assessment of intra-aortic pressure development, a significant decrease in $\mathrm{FL} \Delta \mathrm{P}_{\max }$ was observed in patients with enlarging vs stable aortic dimensions $(32.3 \pm 10.8$ vs. $57.2 \pm 12.5 \mathrm{mmHg} / \mathrm{m}, \mathrm{p}=0.017)$; however, no difference was observed between $\mathrm{FL} \Delta \mathrm{P}_{\min }$
$(-17.6 \pm 6.6$ vs. $-28.7 \pm 9.8 \mathrm{mmHg} / \mathrm{m}, \mathrm{p}=0.105)$. Two subjects (one with stable, and one with enlarging aortic growth) had TL values excluded from analysis due to severe TL narrowing in the descending aorta leading to data loss (average TL radius $<2$ image voxels). Among the remaining analyzed patients, no significant differences in TL maximum relative pressure $(46.6 \pm 7.5$ vs $51.9 \pm 11.6 \mathrm{mmHg} / \mathrm{m}, \mathrm{p}=0.418)$, and TL minimum relative pressure $(-23.6 \pm 5.7$ vs. $-21.6 \pm 6.1 \mathrm{mmHg} / \mathrm{m}$, $\mathrm{p}=0.654)$ were observed between stable and enlarging groups. Table 2 provides a summary of all evaluated hemodynamic parameters. Representative examples of FL hemodynamic evaluation for patients with varying degrees of aortic growth are shown in Fig. 2. Note that no difference in velocity-to-noise (VNR) could be inferred in the 4D Flow CMR data as a function of the two different contrast agents $(32.5 \pm 13.0$ vs. $41.5 \pm 17.6, p=0.209$, for ferumoxytol vs. gadolinium). Here, VNR was calculated using the relationship given in Beerbaum et al. [30], being directly proportional to the velocity encoding divided by the standard deviation of velocity noise in the static tissue (extracted from a region of interest positioned in the posterior back muscles).

\section{Correlation analyses}

None of the baseline anatomic or demographic variables such as maximum aortic baseline diameter $(r=0.45$,

Table 2 Hemodynamics parameters derived from 4D Flow CMR

\begin{tabular}{|c|c|c|c|c|}
\hline Characteristics & Overall $(n=12)$ & Stable $(n=4)$ & Enlarging $(n=8)$ & p-value \\
\hline \multicolumn{5}{|l|}{ Ascending aorta } \\
\hline Cardiac Output (I/min) & $4.9 \pm 0.9$ (range $3.3-6.4)$ & $5.1 \pm 0.9$ & $4.8 \pm 1.0$ & 0.621 \\
\hline Forward Flow (ml/beat) & $87.4 \pm 21.7$ (range 58.2-125.2) & $90.9 \pm 24.7$ & $85.7 \pm 21.6$ & 0.734 \\
\hline Reverse Flow (ml/beat) & $-7.7 \pm 7.5($ range $-26.8-0.5)$ & $-5.2 \pm 3.2$ & $-8.9 \pm 8.9$ & 0.314 \\
\hline \multicolumn{5}{|l|}{ True lumen } \\
\hline Net flow $(1 / \mathrm{min})$ & $3.4 \pm 1.1$ (range $2.1-5.5$ ) & $3.0 \pm 1.0$ & $3.6 \pm 1.1$ & 0.474 \\
\hline Peak velocity $(\mathrm{cm} / \mathrm{s})$ & $89 \pm 32$ (range 38-166) & $84 \pm 7$ & $91 \pm 40$ & 0.653 \\
\hline Maximum relative pressure $(\mathrm{mmHg} / \mathrm{m})^{*}$ & $50 \pm 11$ (range 41-75) & $47 \pm 8$ & $52 \pm 12$ & 0.418 \\
\hline Minimum relative pressure $(\mathrm{mmHg} / \mathrm{m})^{*}$ & $-22 \pm 6$ (range -32 to -15$)$ & $-24 \pm 6$ & $-22 \pm 6$ & 0.654 \\
\hline \multicolumn{5}{|l|}{ Falselumen } \\
\hline Net flow (I/min) & $1.5 \pm 1.4$ (range $0.1-4.6)$ & $1.9 \pm 2.2$ & $1.2 \pm 0.9$ & 0.596 \\
\hline Peak velocity at entry tear (cm/s) & $102 \pm 10$ (range 68-144) & $108 \pm 12$ & $99 \pm 9$ & 0.560 \\
\hline Peak velocity $(\mathrm{cm} / \mathrm{s})$ & $68 \pm 31$ (range 16-120) & $67 \pm 40$ & $69 \pm 29$ & 0.925 \\
\hline False lumen ejection fraction (\%) & $36 \pm 25$ (range $0-88$ ) & $10 \pm 12$ & $49 \pm 18$ & 0.002 \\
\hline Maximum systolic deceleration rate $\left(\mathrm{cm} / \mathrm{s}^{3}\right)$ & $1401 \pm 956$ (range 516-3201) & $1146 \pm 782$ & $1529 \pm 1058$ & 0.499 \\
\hline Maximum relative pressure $(\mathrm{mmHg} / \mathrm{m})$ & $41 \pm 16($ range $21-72)$ & $57 \pm 13$ & $32 \pm 11$ & 0.017 \\
\hline Minimum relative pressure $(\mathrm{mmHg} / \mathrm{m})$ & $-21 \pm 9($ range -42 to -11$)$ & $-29 \pm 10$ & $-18 \pm 7$ & 0.105 \\
\hline \multicolumn{5}{|l|}{ Transseptal } \\
\hline Maximum relative pressure $(\mathrm{mmHg} / \mathrm{m})^{*}$ & $35 \pm 23$ (range 1-66) & $25 \pm 36$ & $39 \pm 18$ & 0.585 \\
\hline Minimum relative pressure $(\mathrm{mmHg} / \mathrm{m})^{*}$ & $-14 \pm 11$ (range -34 to -4$)$ & $-14 \pm 18$ & $-14 \pm 10$ & 0.989 \\
\hline
\end{tabular}

For characteristics marked *, subjects were excluded due to excessive TL narrowing 


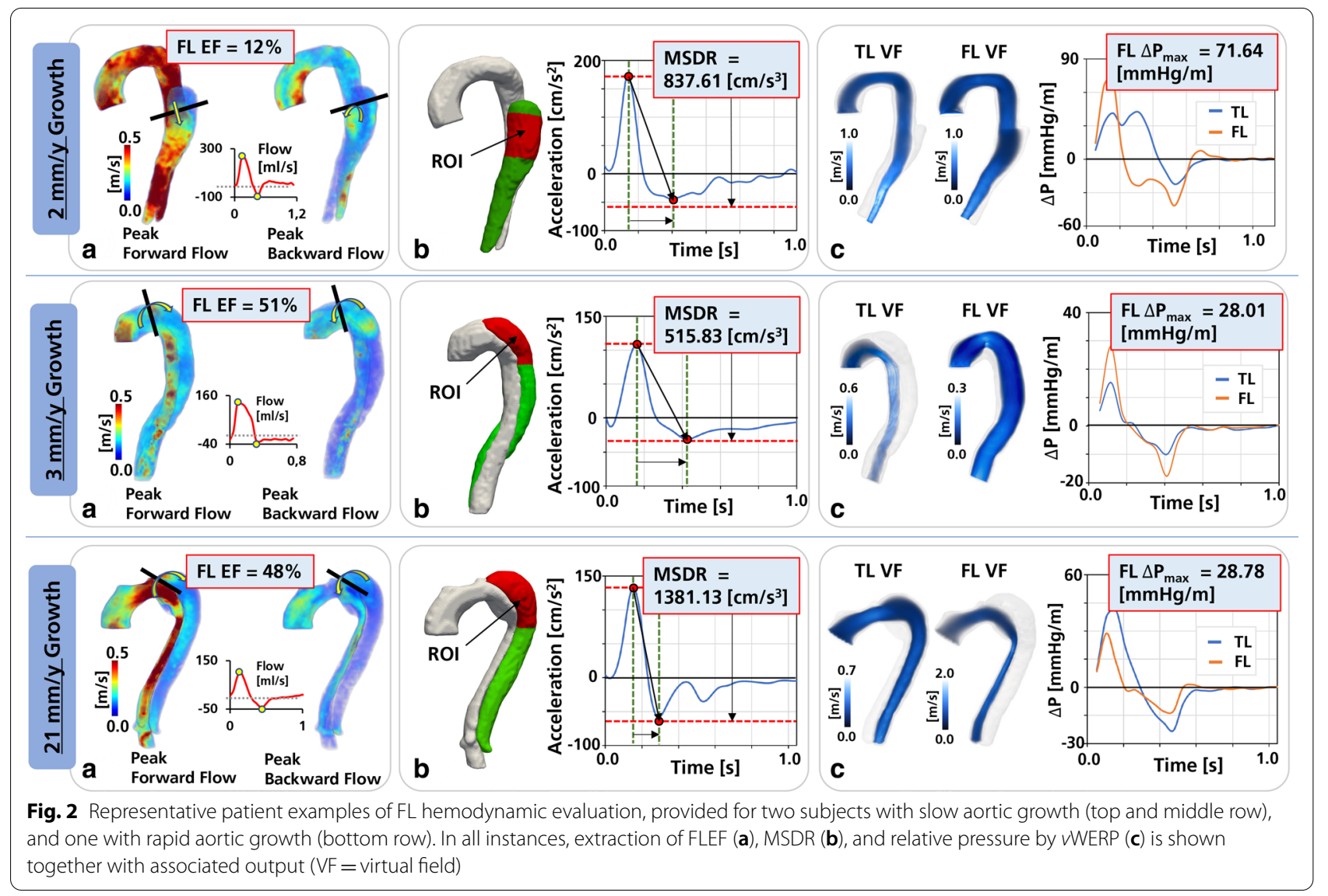

$\mathrm{p}=0.143)$, entry tear size $(\mathrm{r}=-0.21, \mathrm{p}=0.509)$, entry tear distance from the left subclavian artery $(r=0.22$, $\mathrm{p}=0.497)$, dissection length $(\mathrm{r}=0.23, \mathrm{p}=0.466)$, systolic blood pressure $(r=0.11, p=0.745)$, heart rate $(r=-0.20$, $\mathrm{p}=0.533)$ or pulse pressure $(\mathrm{r}=0.50, \mathrm{p}=0.100)$ were significantly correlated with aortic growth rate on bivariate analysis. Only one correlation between anatomic and hemodynamic parameters was statistically significant: entry tear distance from left subclavian artery vs. FL peak velocity $(-0.72, \mathrm{p}=0.009)$.

Among the three investigational metrics, FLEF showed a strong positive correlation with growth rate $(r=0.78$, $\mathrm{p}=0.003)$, whereas FL $\Delta \mathrm{P}_{\max }$ showed a moderatestrong negative correlation with growth rate $(\mathrm{r}=-0.64$, $\mathrm{p}=0.026)$. FLEF and FL $\Delta \mathrm{P}_{\max }$ also demonstrated a moderate-strong correlation with each other $(r=-0.67$, $\mathrm{p}=0.017$ ); however, these quantities did not correlate with any other hemodynamic or anatomic parameters (including entry tear size, tear distance from left subclavian artery, systolic blood pressure, and pulse pressure). FL $\Delta \mathrm{P}_{\min }$ also demonstrated a significant, but slightly weaker correlation with growth rate $(\mathrm{r}=0.59, \mathrm{p}=0.043)$ than FL $\Delta \mathrm{P}_{\max }$, and was strongly correlated with $\mathrm{FL}$ $\Delta \mathrm{P}_{\max }(\mathrm{r}=-0.96, \mathrm{p}<0.001)$. MSDR demonstrated a weak-moderate, but non-significant correlation with aortic growth rate $(r=0.40, p=0.203)$, and a moderatestrong positive correlation to TL peak velocity $(r=0.64$, $p=0.004)$. MSDR did not correlate with FLEF $(r=0.37$, $\mathrm{p}=0.24)$, FL $\Delta \mathrm{P}_{\max }(\mathrm{r}=-0.11, \mathrm{p}=0.73)$ or $\mathrm{FL} \Delta \mathrm{P}_{\min }$ $(\mathrm{r}=0.12, \mathrm{p}=0.71)$. Cardiac output and heart rate were not correlated with FLEF, FL $\Delta \mathrm{P}_{\max }$, or MSDR. Scatter plots depicting the correlation between aortic growth rate and key parameters are shown in Fig. 3.

\section{Multivariate analyses-predictors of aortic growth rate}

Multiple linear regression analysis models were performed to identify the independent association of FLEF, FL maximum relative pressure and MSDR on aortic growth rate after adjusting for baseline maximal diameter (three separate multivariate analyses were utilized to avoid multicollinearity). On adjusted analysis, FLEF was independently associated with aortic growth rate $(\beta=0.23, \quad p<0.001)$ with an overall model adjusted $\mathrm{R}^{2}=0.85$. Similarly, FL $\Delta \mathrm{P}_{\max }$ was also independently associated with aortic growth rate $(\beta=-0.22, p=0.012)$, 

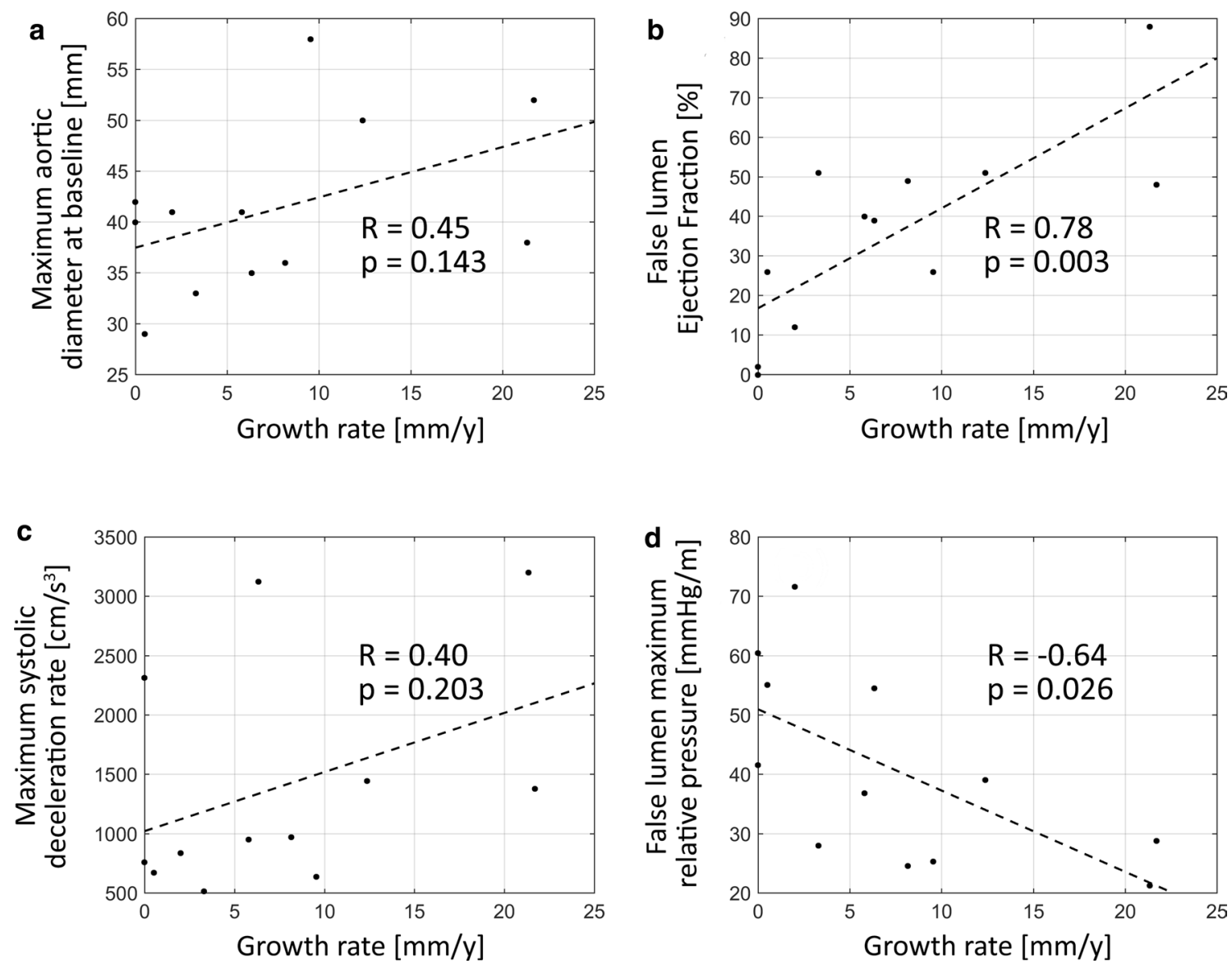

Fig. 3 Scatter plots depicting the correlation between aortic growth rate and $\mathbf{a}$ baseline maximal aortic diameter, $\mathbf{b}$ false lumen ejection fraction, $\mathbf{c}$ maximum systolic deceleration rate, and $\mathbf{d}$ false lumen maximum relative pressure

Table 3 Multivariate regression assessment-evaluating independent predictors of aortic growth rate

\begin{tabular}{|c|c|c|c|}
\hline Characteristics & $\beta$ coefficient & $95 \% \mathrm{Cl}$ & p-value \\
\hline \multicolumn{4}{|c|}{ Predictors of growth rate with FL EF (adjusted $R^{2}=0.85$ ) } \\
\hline FLEF & 0.23 & $0.18,0.32$ & $<0.001$ \\
\hline $\begin{array}{l}\text { Baseline maximum aortic } \\
\text { diameter }\end{array}$ & 0.45 & $0.12,0.79$ & 0.013 \\
\hline \multicolumn{4}{|c|}{ Predictors of growth rate with $F L \Delta P_{\max }\left(\right.$ adjusted $\left.R^{2}=0.60\right)$} \\
\hline $\begin{array}{l}\text { FL maximum relative } \\
\text { pressure }\end{array}$ & -0.22 & $-0.50,-0.01$ & 0.012 \\
\hline $\begin{array}{l}\text { Baseline maximum aortic } \\
\text { diameter }\end{array}$ & 0.27 & $-0.27,0.81$ & 0.283 \\
\hline \multicolumn{4}{|c|}{ Predictors of growth rate with MSDR (adjusted $R^{2}=0.42$ ) } \\
\hline MSDR & 0.003 & $-0.002,0.009$ & 0.151 \\
\hline $\begin{array}{l}\text { Baseline maximum aortic } \\
\text { diameter }\end{array}$ & 0.47 & $0.50,0.88$ & 0.031 \\
\hline
\end{tabular}

$F L$ false lumen, $F L E F$ false lumen ejection fraction, MSDR maximum systolic deceleration rate with an overall model adjusted $R^{2}=0.60$. However, MSDR was not found to be independently associated with aortic growth rate after adjusting for baseline diameter $(\beta=-0.003, p=0.151)$. Full data is shown in Table 3 .

\section{Reproducibility analysis}

Complete results for the reproducibility analysis are provided in Additional file 1: Appendix B. Comparing aortic growth rate assessed by different raters, strong correlation was observed $(\mathrm{r}=0.94, \mathrm{p}<0.001)$. A modest interrater difference of $1.5 \pm 2.8 \mathrm{~mm} /$ year was noted for aortic growth rate, although without significant bias and with concordant growth categorization (stable vs. enlarging) between raters in all cases (see Additional file 1: Appendix Figure B.1 and Table B.1 for complete data).

The two rater's measurements of FLEF were also strongly correlated $(\mathrm{r}=0.86, \mathrm{p}<0.001)$, with a mean difference of $-1.6 \pm 13.4 \%$. For FL $\Delta \mathrm{P}_{\max }$, strong correlation was observed after repeat mask registration and with additional systematic variations in segmentation $(r>0.94, p<0.001)$, with the largest difference observed 
for masks with systematically dilated segmentations (- $2.7 \pm 9.2 \mathrm{mmHg} /$ year). For MSDR, moderate-strong correlation also persisted over all variations in segmentation $(\mathrm{r}>0.75, \mathrm{p}<0.005)$, with the largest difference observed for systematically eroded segmentations $(-133 \pm 685)$ (complete data presented in Additional file 1: Appendix B).

\section{Discussion}

In this study, we examined the ability of three 4D Flow CMR derived methods of estimating FL pressurization to predict growth in patients with chronic dissection of the descending thoracic aorta: FLEF, MSDR, and $v$ WERP-derived FL maximum relative pressure (FL $\left.\Delta \mathrm{P}_{\max }\right)$. We have shown that FL hemodynamics are significantly altered in patients with aortic growth: FLEF was significantly increased and FL $\Delta \mathrm{P}_{\max }$ was significantly decreased. Neither MSDR, nor any of the anatomical metrics (such as baseline maximum aortic diameter) clearly differentiated enlarging from stable patients. TL and transseptal hemodynamic parameters did not differ between groups, which is unsurprising considering aortic growth in TBAD is the direct consequence of FL enlargement. Furthermore, FLEF and FL $\Delta \mathrm{P}_{\max }$ demonstrated moderate-strong correlation with each other, and both were found to be independent predictors of aortic growth after adjusting for baseline aortic diameter. This work is the first application of $\nu$ WERP to provide a direct pressure assessment of the FL in TBAD patients, and to understand the relation between direct and indirect techniques for assessing FL pressure using 4D Flow CMR. These results lend further credence to the importance of FL pressurization in promoting growth in TBAD, and support further investigation of FLEF and FL $\Delta \mathrm{P}_{\max }$ as hemodynamic biomarkers of risk in TBAD patients.

\section{Current approaches and mechanisms of aortic growth}

Current treatment protocols and surgical criteria are largely based on anatomic variables, the most important of which is maximum aortic diameter [7]. Aortic diameter is a simple metric, and has a direct relationship with tensile wall stress (i.e., Law of Laplace). However, in a recent systematic review of growth in TBAD, maximal aortic diameter was associated with growth in only 50\% of studies, highlighting the need for better risk stratification tools [7]. While our results support the association between baseline diameter and aortic growth we also found that FLEF and FL $\Delta \mathrm{P}_{\max }$ provided additional predictive value over baseline diameter alone. This is likely due to the fact that anatomic variables such as aortic diameter are a consequence of aortic wall pathology rather than a direct cause of it. While aortic growth is the result of a complex set of factors (e.g., hemodynamic stress, mechanobiological responses, aortic tissue strength), most of these factors are challenging to noninvasively measure in patients, highlighting the unique value of hemodynamic assessment by 4D Flow CMR.

\section{Metrics of false lumen pressurization}

In this study, we chose to assess the predictive value of three different methods of assessing FL hemodynamic stress: FLEF, MSDR, and FL $\Delta \mathrm{P}_{\max }$. These three metrics represent different ways of-either directly or indirectly-describing the relationship between flow and pressure in the FL, and the three also represent different ways of interrogating the acquired flow field: utilizing bulk flow, acceleration rate, or relative pressure, respectively.

FLEF has been previously described in TBAD [18], with this metric describing the ratio between retrograde and antegrade flow through the dominant entry tear. FLEF is a regional and indirect measure of assessing FL pressurization. An increasing proportion of FL inflow relative to outflow will result in increased FL pressure (particularly diastolic pressure [12]) and increased resistance to forward flow. During diastole, flow reversal occurs when FL diastolic pressure supersedes diastolic pressure in the $\mathrm{TL}$, and this reversed pressure gradient drives blood from the FL into the TL across entry tears. This ratio of retrograde and antegrade flow at the entry tear, mediated by diastolic pressure gradients, can thus be posed as a surrogate measure of the pressure difference between FL and TL (a conceptual illustration of the relationship between antegrade/retrograde and aortic growth is show in Fig. 4). Interestingly, the relationship between retrograde flow and pressure overload has been described not only in the FL of TBAD patients, but also as a maker of pulmonary hypertension severity [31]. Advantages to the FLEF approach include: bulk flow rate measurements in TBAD with 4D Flow CMR have been shown to be highly reproducible [32] and are easily performed using a variety of commercially available software, flow measurements are performed at a discreet anatomic location (i.e., entry tear) and are thus fairly robust to variations in dissection anatomy, and this approach avoids technical difficulty and potential inaccuracy related to conversion of spatiotemporal flow gradients in its computation. However, FLEF does not directly measure pressure, does not take into account the hemodynamics at distal re-entry tears, and the definition of a 2-dimensional flow analysis plane can be difficult if entry tear anatomy is complex. Nevertheless, the moderate-strong correlation between FLEF and aortic growth in our data underlines this metrics potential clinical utility.

Alternatively, MSDR is a recently proposed semiregional, indirect method of assessing FL pressurization 


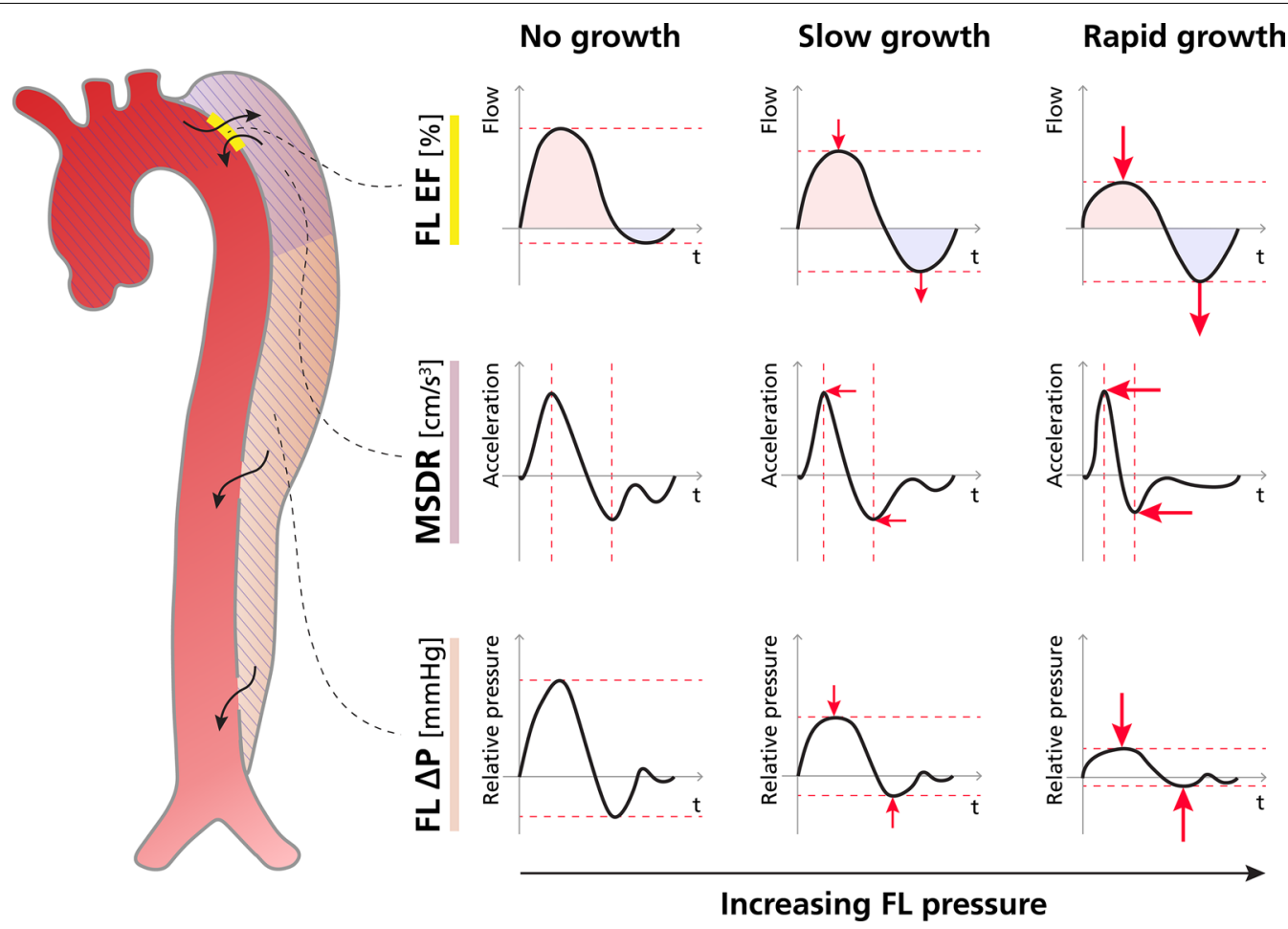

Fig. 4 Conceptual model depicting the proposed relations between growth and 4D Flow-derived markers of FL pressurization. False lumen ejection fraction (FLEF): The top row depicts increased retrograde flow (light blue) relative to antegrade flow (light red) with increasing aortic growth rate, hypothesized to be related to increased FL pressurization. Maximum systolic deceleration rate (MSDR): The middle row depicts the acceleration of blood through a proximal portion of the FL (the light purple shaded area), with MSDR representing the mean rate of change between peak acceleration and peak deceleration (i.e. the downward slope between peaks). With increasing FL pressurization, higher resistance FL flow leads to faster flow deceleration (i.e. a more pronounced, steeper slope). FL maximal relative pressure ( $\left.F L \Delta P_{\max }\right)$ : The bottom row depicts the observed trend between decreased relative pressure between the aortic root and the distal FL (the striped region in the TBAD to the left) and increasing aortic growth rate. Increased FL pressurization leads to increased resistance to flow, and thus dampening of relative pressure gradients

[24], representing the average peak systolic deceleration rate in a proximal sub-section of the FL. As with FLEF, the coupling to FL pressurization is intuitive: with increasing FL pressures, resistance to forward flow will increase, antegrade systolic flow will decelerate more rapidly, and the MSDR will consequently increase (see Fig. 4 for a conceptual depiction of changes in MSDR with increasing aortic growth). MSDR was recently introduced and studied in a cohort of 29 patients (combined repaired type A dissection and TBAD), where a weak-moderate, positive correlation with aortic growth rate $(r=0.48)$ was reported [24]. While we identified a similarly weak-moderate positive correlation between MSDR and aortic growth rate $(r=0.40)$, this correlation did not reach statistical significance, possibly owing to the smaller size of our cohort. However, the weaker correlation between MSRD and aortic growth compared to FLEF and FL $\Delta \mathrm{P}_{\max }$ may be a result of the MSDR metric itself, given that the MSDR measurement relies on SNR and the temporal sampling rate of the acquired flow field, which can be variable in TBAD. Furthermore, the presence of significant secondary flow features (e.g., helices and vortices) may affect MSDR measurements, and appropriate definition of the analysis subsection becomes less clear when the entry tear is located more distally along the descending aorta.

While FLEF and MSDR are proposed as indirect measures of FL pressure, recent developments in physicsbased image analysis now enable the accurate extraction of relative pressure over vascular sections. $v$ WERP is a validated method for relative pressure measurement that utilizes the concept of virtual work-energy, which has shown particular promise in assessing complex vasculatures and has been explicitly tested in TBAD anatomy [25]. As such, the FL $\Delta \mathrm{P}_{\max }$ represents a global and direct measure of change in pressure from the ascending aorta to the distal thoracic FL. FL $\Delta \mathrm{P}_{\max }$ should thus decrease with increasing FL pressure (and constant ascending pressure) and growth. This is concordant with our observed moderate-strong negative correlation between FL $\Delta \mathrm{P}_{\max }$ and aortic growth rate (see Fig. 4 for a conceptual depiction of changes in FL relative 
pressure with increasing aortic growth). Similar to FLEF and MSDR, $v$ WERP can be derived from 4D Flow data alone, however, the method does require the creation of an auxiliary virtual field in order to compute relative pressure. Although not an overly time-consuming process ( 5 min on a local desktop computer), $v$ WERP computation requires aortic segmentation, which can be time-consuming in TBAD, and separate computational implementation, making it a more complex analysis than other measures such as FLEF. Lastly, an advantage of the vWERP approach is that relative pressure is derived over the entire thoracic aorta, and thus the global hemodynamic state of the FL is accounted for in its computation.

When considering the differences between FLEF and $\mathrm{FL} \Delta \mathrm{P}_{\max }$, we found a slightly stronger correlation of FLEF with aortic growth compared to FL $\Delta \mathrm{P}_{\max }$ on both adjusted and unadjusted analyses $(r=0.78$ vs. $r=-0.64$, Fig. 3), although it's unclear if such small differences in strength of correlation are meaningful or simply related to statistical noise. The simplicity in derivation makes FLEF an attractive metric in clinical instances where the FL has a single dominant tear in the thoracic aorta, whereas $v$ WERP may be better suited in scenarios with multiple or complex flap fenestrations/tears (as shown in previous in-silico work [25]. Regardless of the metric, our analysis underlines the pathophysiological importance of FL pressurization in TBAD growth, adding to the increasing number of studies highlighting its diagnostic role $[10-13,18,24,33]$. In reality, since both FLEF and FL $\Delta \mathrm{P}_{\max }$ can be measured from the same $4 \mathrm{D}$ Flow acquisition, measurement of multiple parameters may be a complementary approach that lends additional diagnostic certainty in cases where pressurization assessments are concordant.

Lastly, it is important to acknowledge potential sources of measurement variability in these hemodynamic metrics: manual plane placement at the entry tear for FLEF, and aortic segmentation for MSDR and FL $\Delta \mathrm{P}_{\max }$. The results from our reproducibility analyses address this in detail (Additional file 1: Appendix B). In brief, for the three derived hemodynamic metrics we identified no significant inter-rater bias, although agreement was highest for FL $\Delta \mathrm{P}_{\max }$ and lowest for FLEF. However, the degree of variability for FLEF and FL $\Delta \mathrm{P}_{\max }$ were substantially lower than the mean differences in these metrics between stable and enlarging groups, suggesting that this degree of variability is still acceptable for separating patients at high and lower risk of growth. Additionally, FL $\Delta \mathrm{P}_{\max }$ demonstrated higher variability related to aortic mask dilation rather than erosion into the lumen, a behavior that is consistent with prior $v$ WERP results [34]. Along the same lines, modest interrater differences were noted with measurement of aortic growth rate, an observation which is not surprising given the known variability of diameter measurement in dissected aortas; however, growth categorizations (stable vs. enlarging) remained concordant between readers and for all cases despite this measurement variability. Nevertheless, care must be taken when deriving any of the aforementioned metrics in future scientific or clinical studies, and raters with experience in accurately delineating dissection anatomy are key for reliable anatomic or hemodynamic assessment.

\section{Limitations}

Our study has several limitations. First, our study cohort was relatively small in size, and thus these findings should be interpreted as preliminary and hypothesis generating, although efforts to study these metrics in larger cohorts are ongoing. In part our small sample size was due to the fact that we excluded 3 patients for non-contrast exams (inability to accurately segment the TL and FL) and another 3 patients for arrhythmia-related artifacts. However, we believe that these results can be viewed as a representative example of how advanced flow imaging can provide unique insights into the complex hemodynamic mechanism of TBAD.

Second, exclusively chronic dissections were analyzed in our study, and as such it is impossible to infer causal relationships between aortic growth and our three investigational metrics. However, given that abnormal FL blood flow been linked to aneurysmal growth in previous imaging studies of acute TBAD patients [8] and in computational studies [35], we believe it is reasonable to assume that such abnormal hemodynamics are a precursor of progressive FL growth. Efforts are ongoing to validate these findings in acute/subacute TBAD patients.

Third, although not unique to our study, the acquisition of 4D Flow CMR data is not available or part of routine clinical CMR protocols at most centers, although such data can be acquired on almost all modern clinical CMR systems. Further investigation into the specific clinical utility of these metrics of FL pressurization will be needed to promote more wide-spread clinical translation. Lastly, aortic growth was determined by measuring diameter changes between different modalities (e.g., $\mathrm{CT}$ at baseline and MRA at follow-up). However, a recent study comparing inter-modality differences in aortic measurements indicate only small and non-significant differences when a consistent measurement technique is used [28], as was done in this study.

\section{Conclusions}

Using non-invasive 4D Flow CMR, three different metrics of FL pressurization were evaluated in conjunction with aortic dissection growth: FLEF, MSDR, and FL 
$\Delta \mathrm{P}_{\max }$. FLEF and FL $\Delta \mathrm{P}_{\max }$ were correlated with each other, and both differentiated patients with stable vs. enlarging aortic dimensions and both were predictive of aortic growth rate after adjustment for baseline aortic diameter. Conversely, MSDR did not significantly correlate with aortic growth or other investigational hemodynamic metrics. Overall, these results highlight the possible clinical value of non-invasive FL pressurization assessment in patients with aortic dissection of the descending aorta, and highlight the potential role of 4D Flow CMR in providing patient-specific hemodynamic assessments for improved patient management.

\begin{abstract}
Abbreviations
$\Delta p_{\text {max }}$ : Relative pressure; CE-MRA: Contrast enhanced magnetic resonance angiography; Cl: Confidence interval; CMR: Cardiovascular magnetic resonance; CT: Computed tomography; FL: False lumen; FLEF: False lumen ejection fraction; IQR: Interquartile range; MSDR: Maximum systolic deceleration rate; PC- MRA: Phase contrast magnetic resonance angiography; SD: Standard deviation; TBAD: Type B aortic dissection; TEVAR: Thoracic aortic endovascular repair; TL:True lumen; VNR: Velocity to noise; VWERP: Virtual work-energy relative pressure.
\end{abstract}

\section{Supplementary Information}

The online version contains supplementary material available at https://doi. org/10.1186/s12968-021-00741-4.

Additional file 1. Additional material - Appendix A (Relative pressure estimation by vWERP) and B (Reproducibility analysis).

\section{Acknowledgements}

We would like to acknowledge Drs. Bo Yang, Karen Kim, Shinichi Fukuhara and G. Michael Deeb, and clinical coordinators Mary Passow, Lynn Hendee, Susan Hooker and Maureen Daly for their assistance with patient enrollment, as well as our research MRI staff including James Pool, Ladonna Austin, Suzan Lowe and James O'Conner for their assistance with enrollment and CMR examinations.

\section{Authors' contributions}

NB, JS, DM and DN conceived of the study. NB and HP was responsible for the data collection. DM, JS, RGK and NB performed the data analysis. DM, JS and NB wrote the manuscript, with input from all authors. All authors read and approved the final manuscript.

\section{Funding}

NSB - Radiologic Society of North America Research Scholar Grant (RSCH1801) and US National Institute of Health (R44 HL14595). DM-Wallenberg Foundation scholarship program for postdoctoral studies at Massachusetts Institute of Technology (MIT) and Broad Institute. JAS-ANID-FONDECYT de Iniciación en Investigación (\#11200481). JAS/SU-ANID-Millennium Science Initiative Program, NCN17 129, PIA-ACT192064, CONICYT_FONDECYT (\#1181057), ANID FONDECYT de Iniciación en Investigación (\#1180832) and CONICYT_FONDECYT Postdoctorado 2017 (\#3170737), all from the Chilean National Agency for Research and Development, ANID. DAN_Funding from the Engineering and Physical Sciences Research Council (EP/N011554/1 and EP/R003866/1). HJP- Joe D. Morris Collegiate Professorship, Phil Jenkins Breakthrough Fund and David Hamilton Fund in Cardiac Surgery. ERE-Funding from the US National Institute of Health (R01 49039).

\section{Availability of data and materials}

The datasets used and/or analyzed during the current study contain patient data, but can access can be requested from the corresponding author on reasonable request and after appropriate agreements.

\section{Declarations}

Ethics approval and consent to participate

Participants provided informed written consent prior to participation in the study. This study was part of an IRB-approved study (HUM00120679) and was conducted in accordance with the Declaration of Helsinki guidelines.

\section{Consent for publication}

Not applicable.

\section{Competing interests}

The authors declare that they have no competing interests.

\section{Author details}

${ }^{1}$ Institute for Medical Engineering and Science, Massachusetts Institute of Technology, Cambridge, MA, USA. ${ }^{2}$ School of Biomedical Engineering, Universidad de Valparaíso, Valparaíso, Chile. ${ }^{3}$ Biomedical Imaging Center, Pontificia Universidad Católica de Chile, Santiago, Chile. ${ }^{4}$ ANID-Millennium Science Initiative Program-Millennium Nucleus in Cardiovascular Magnetic Resonance, Santiago, Chile. ${ }^{5}$ Department of Radiology, Schools of Medicine, Pontificia Universidad Católica de Chile, Santiago, Chile. ${ }^{6}$ Department of Biomedical Engineering, University of Michigan, Ann Arbor, MI, USA. ${ }^{7}$ Department of Cardiac Surgery, University of Michigan, Ann Arbor, MI, USA. ${ }^{8}$ School of Biomedical Engineering and Imaging Sciences, King's College London, London, UK. ${ }^{9}$ Department of Radiology, University of Michigan, 1500 E. Medical Center Drive, Cardiovascular Center 5588, SPC-5030, Ann Arbor, MI 48109-5030, USA.

Received: 9 September 2020 Accepted: 16 March 2021

Published online: 13 May 2021

\section{References}

1. Tsai TT, Evangelista A, Nienaber CA, Trimarchi S, Sechtem U, Fattori R, et al. Long-term survival in patients presenting with type A acute aortic dissection: insights from the International Registry of Acute Aortic Dissection (IRAD). Circulation. 2006;1 14(1_supplement):I-350-I-356.

2. Durham CA, Cambria RP, Wang LJ, Ergul EA, Aranson NJ, Patel VI, et al. The natural history of medically managed acute type B aortic dissection. J Vasc Surg. 2015;61(5):1192-9.

3. Nienaber CA, Kische S, Rousseau H, Eggebrecht H, Rehders TC, Kundt G, et al. Endovascular repair of type $B$ aortic dissection: long-term results of the randomized investigation of stent grafts in aortic dissection trial. Circ Cardiovasc Interv. 2013;6(4):407-16.

4. Fattori R, Montgomery D, Lovato L, Kische S, Di Eusanio M, Ince H, et al. Survival after endovascular therapy in patients with type B aortic dissection: a report from the International Registry of Acute Aortic Dissection (IRAD). JACC Cardiovasc Interv. 2013;6(8):876-82.

5. Desai ND, Gottret J-P, Szeto WY, McCarthy F, Moeller P, Menon R, et al. Impact of timing on major complications after thoracic endovascular aortic repair for acute type B aortic dissection. J Thorac Cardiovasc Surg. 2015;149(2):S151-6.

6. Famularo M, Meyermann K, Lombardi JV. Aneurysmal degeneration of type B aortic dissections after thoracic endovascular aortic repair: a systematic review. J Vasc Surg. 2017;66(3):924-30.

7. Spinelli D, Benedetto F, Donato R, Piffaretti G, Marrocco-Trischitta MM, Patel HJ, et al. Current evidence in predictors of aortic growth and events in acute type B aortic dissection. J Vasc Surg. 2018;68(6):1925-35.e8.

8. Sailer AM, Van Kuijk SM, Nelemans PJ, Chin AS, Kino A, Huininga M, et al. Computed tomography imaging features in acute uncomplicated Stanford type-B aortic dissection predict late adverse events. Circ Cardiovasc Imaging. 2017;10(4):e005709.

9. Schwartz SI, Durham C, Clouse WD, Patel VI, Lancaster RT, Cambria RP, et al. Predictors of late aortic intervention in patients with medically treated type B aortic dissection. J Vasc Surg. 2018;67(1):78-84.

10. Rudenick PA, Bijnens BH, García-Dorado D, Evangelista A. An in vitro phantom study on the influence of tear size and configuration on the hemodynamics of the lumina in chronic type B aortic dissections. J Vasc Surg. 2013;57(2):464-74. e5. 
11. Zadrazil I, Corzo C, Voulgaropoulos V, Markides CN, Xu XY. A combined experimental and computational study of the flow characteristics in a Type B aortic dissection: effect of primary and secondary tear size. Chem Eng Res Design. 2020;160:240-53.

12. Tsai TT, Schlicht MS, Khanafer K, Bull JL, Valassis DT, Williams DM, et al. Tear size and location impacts false lumen pressure in an ex vivo model of chronic type B aortic dissection. J Vasc Surg. 2008;47(4):844-51.

13. Qing K-X, Chan Y-C, Ting A, Cheng S. Persistent intraluminal pressure after endovascular stent grafting for type B aortic dissection. Eur J Vasc Endovasc Surg. 2016;51(5):656-63.

14. Dillon-Murphy D, Noorani A, Nordsletten D, Figueroa CA. Multi-modality image-based computational analysis of haemodynamics in aortic dissection. Biomech Model Mechanobiol. 2016;15(4):857-76.

15. Keramati H, Birgersson E, Ho JP, Kim S, Chua KJ, Leo HL. The effect of the entry and re-entry size in the aortic dissection: a two-way fluid-structure interaction simulation. Biomech Model Mechanobiol. 2020. https://doi. org/10.1007/s10237-020-01361-0.

16. Rudenick PA, Segers P, Pineda V, Cuellar H, García-Dorado D, Evangelista A, et al. False lumen flow patterns and their relation with morphological and biomechanical characteristics of chronic aortic dissections. Computational model compared with magnetic resonance imaging measurements. PLoS ONE. 2017;12(1):0170888.

17. Ahmed SB, Dillon-Murphy D, Figueroa C. Computational study of anatomical risk factors in idealized models of type B aortic dissection. Eur J Vasc Endovasc Surg. 2016;52(6):736-45.

18. Burris NS, Nordsletten DA, Sotelo JA, Grogan-Kaylor R, Houben IB, Figueroa $C A$, et al. False lumen ejection fraction predicts growth in type B aortic dissection: preliminary results. Eur J Cardiothorac Surg. 2020;57(5):896-903

19. Clough RE, Waltham M, Giese D, Taylor PR, Schaeffter T. A new imaging method for assessment of aortic dissection using four-dimensional phase contrast magnetic resonance imaging. J Vasc Surg. 2012;55(4):914-23.

20. Burris NS, Patel HJ, Hope MD. Retrograde flow in the false lumen: marker of a false lumen under stress? J Thorac Cardiovasc Surg. 2019;157(2):488-91.

21. François CJ, Markl M, Schiebler ML, Niespodzany E, Landgraf BR, Schlensak $C$, et al. Four-dimensional, flow-sensitive magnetic resonance imaging of blood flow patterns in thoracic aortic dissections. J Thorac Cardiovasc Surg. 2013;145(5):1359-66

22. Stankovic Z, Allen BD, Garcia J, Jarvis KB, Markl M. 4D flow imaging with MRI. Cardiovasc Diagn Therapy. 2014;4(2):173-92.

23. Allen BD, Aouad PJ, Burris NS, Rahsepar AA, Jarvis KB, François CJ, et al. Detection and hemodynamic evaluation of flap fenestrations in type $B$ aortic dissection with 4D flow MRI: comparison with conventional MRI and CT angiography. Radiol Cardiothorac Imaging. 2019;1(1):e180009.

24. Ruiz Munoz A, Guala A, Teixido-Tura G, Dux-Santoy L, Sao-Aviles A, LopezSainz A, et al. P1600 Aortic dilatation in patients with chronic descending aorta dissection is related to maximum false-lumen systolic flow deceleration rate as evaluated by 4D-flow MRI. Eur Heart J Cardiovasc Imaging. 2020;21(Supplement_1):jez319. 1018.
25. Marlevi D, Ruijsink B, Balmus M, Dillon-Murphy D, Fovargue D, Pushparajah $\mathrm{K}$, et al. Estimation of cardiovascular relative pressure using virtual work-energy. Sci Rep. 2019;9(1):1375.

26. Sotelo J, Urbina J, Valverde I, Tejos C, Irarrázaval P, Andia ME, et al. 3D quantification of wall shear stress and oscillatory shear index using a finite-element method in 3D CINE PC-MRI data of the thoracic aorta. IEEE Trans Med Imaging. 2016:35(6):1475-87.

27. Sotelo J, Mura J, Hurtado D, Uribe S, editors. A novel MATLAB toolbox for processing 4D Flow MRI data. International Society of Magnetic Resonance in Medicine (ISMRM); 2019; Montréal, Canada.

28. Frazao C, Tavoosi A, Wintersperger BJ, Nguyen ET, Wald RM, Ouzounian $M$, et al. Multimodality assessment of thoracic aortic dimensions: comparison of computed tomography angiography, magnetic resonance imaging, and echocardiography measurements. J Thorac Imaging. 2020. https://doi.org/10.1097/RTI.0000000000000514.

29. Sueyoshi E, Sakamoto I, Hayashi K, Yamaguchi T, Imada T. Growth rate of aortic diameter in patients with type $\mathrm{B}$ aortic dissection during the chronic phase. Circulation. 2004;110(11_suppl_1):II256-61.

30. Beerbaum P, Körperich H, Gieseke J, Barth P, Peuster M, Meyer H. Rapid left-to-right shunt quantification in children by phase-contrast magnetic resonance imaging combined with sensitivity encoding (SENSE). Circulation. 2003;108(11):1355-61.

31. Helderman F, Mauritz GJ, Andringa KE, Vonk-Noordegraaf A, Marcus JT. Early onset of retrograde flow in the main pulmonary artery is a characteristic of pulmonary arterial hypertension. J Magn Reson Imaging. 2011;33(6):1362-8.

32. de Beaufort HW, Shah DJ, Patel AP, Jackson MS, Spinelli D, Yang EY, Ghosn MG, Autry K, Igo SR, Lumsden AB, Little SH, Trimarchi S, Bismuth J. Fourdimensional flow cardiovascular magnetic resonance in aortic dissection: Assessment in an ex vivo model and preliminary clinical experience. J Thorac Cardiovasc Surg. 2019;157(2):467-76.e1. https://doi.org/10.1016/j. jtcvs.2018.06.022

33. Tsai TT, Evangelista A, Nienaber CA, Myrmel T, Meinhardt G, Cooper JV, et al. Partial thrombosis of the false lumen in patients with acute type $B$ aortic dissection. N Engl J Med. 2007;357(4):349-59.

34. Marlevi D, Balmus M, Hessenthaler A, Viola F, Fovargue D, Vecchi A, et al. Non-invasive estimation of relative pressure for intracardiac flows using virtual work-energy. Med Image Anal. 2020;68:101948.

35. Xu H, Li Z, Dong H, Zhang Y, Wei J, Watton PN, et al. Hemodynamic parameters that may predict false-lumen growth in type-B aortic dissection after endovascular repair: a preliminary study on long-term multiple follow-ups. Med Eng Phys. 2017;50:12-21.

\section{Publisher's Note}

Springer Nature remains neutral with regard to jurisdictional claims in published maps and institutional affiliations.

Ready to submit your research? Choose BMC and benefit from

- fast, convenient online submission

- thorough peer review by experienced researchers in your field

- rapid publication on acceptance

- support for research data, including large and complex data types

- gold Open Access which fosters wider collaboration and increased citations

- maximum visibility for your research: over 100M website views per year

At BMC, research is always in progress.

Learn more biomedcentral.com/submissions 